\title{
The Effect of Mathematics Self-Efficacy on Anxiety of Teaching Mathematics
}

\begin{abstract}
Alattin URAL*
Received: 09 September 2014

Accepted: 06 February 2015

ABSTRACT: The aim of the study is to investigate the effect of mathematics self-efficacy belief on anxiety of teaching mathematics. The participants of the study consist of 42 mathematics teacher candidates in the Department of Mathematics Education, Faculty of Education. The scale of mathematics self-efficacy, developed by Umay (2001), and the scale of mathematics teaching anxiety, developed by Peker (2006), was enrolled as measurement tools. Pearson correlation was used for the correlation between teacher candidates' average points from the both scales. The results revealed that there was a significant and negative correlation mathematics self-efficacy beliefs and anxiety of teaching mathematics. This result means that the students' mathematics teaching anxiety decreases as their mathematics self-efficacy beliefs increase. On the other hand, it was seen that mathematics self-efficacy belief explains $35 \%$ of the variance in teaching mathematics anxiety. Besides, it was determined that mathematics teacher candidates' mathematics teaching anxiety was at low level, and mathematics efficacy beliefs are at high level. Mathematics self-efficacy refers to the belief or perception that one is capable of organizing and executing the actions necessary to succeed at a given mathematical task. For this aim, their knowledge and abilities relating mathematical concepts and also their confidences about their mathematical abilities must be enhanced.
\end{abstract}

Keywords: mathematics self-efficacy, anxiety of teaching mathematics, teacher candidates

\section{Extended Abstract}

Mathematics self-efficacy refers to the belief or perception that one is capable of organizing and executing the actions necessary to succeed at a given mathematical task. Mathematics teaching anxiety can be defined as pre- and in-service teachers' feelings of tension and anxiety that occurs during teaching mathematical concepts, theories, and formulas or during problem solving. The symptoms of mathematics teaching anxiety can include extreme nervousness, the inability to concentrate, negative selftalk, being easily upset by noises, being unable to hear the students, and sweaty palms-to name just a few. Mathematics teaching anxiety appears at organizing the content, planing the time, determining teaching methods and learning activities (Ameen, Guffey \& Jackson 2002; Huber \& Ward, 1969). Teaching anxiety may result from difficulties in answering students’ questions (Ameen, Guffey \& Jackson, 2002).

Anxiety concerning teaching mathematics is a frequent fear of pre-service teachers. Similar problems are common among all the pre-service teachers including pre-service mathematics teachers. It may reflect real or perceived knowledge deficits in mathematics content as well as in mathematics teaching skills, and memories of past occurrences of mathematics failure or anxiety (Levine, 1993). That math teachers are expected to be well qualified about teaching math cause anxiety (Huber \& Ward, 1969; Ameen et. al., 2002). Peker (2006) stated that there were several factors, such as content

\footnotetext{
*Assist. Prof. Dr, Mehmet Akif Ersoy University, Burdur, Turkey, altnurl@gmail.com
} 
knowledge, attitude towards mathematics, and self confidence related to both mathematics anxiety and mathematics teaching anxiety. Akinsola (2008) stated that teaching anxiety has negative correlation with ability of problem solving. Abstract discussions regarding mathematical concepts increased the teaching anxiety of the preservice primary teachers who had a high level of anxiety about teaching mathematics (Levine, 1996), but using manipulative materials, getting familiar with developing creative teaching strategies for mathematics teaching and learning reduced the teaching anxiety level of the pre-service primary school teachers (Levine, 1996; Vinson, 2001). Furthermore, Peker (2008) found that when the need for finding concrete examples for pre-service teachers' teaching is increasing, the pre service teachers' levels of anxiety about mathematics teaching are also increasing. As a result of the study by Peker (2009b), it was determined that the use of expanded microteaching reduced preservice teachers' teaching anxiety about mathematics. Uusimaki and Nason (2004) reported that pre-service teachers' negative beliefs and anxiety about mathematics have a powerful impact on the practice of teaching.

Purpose and Significance: At the end of the review the literature about the factors affecting the anxiety of teaching mathematics, it was seen that mathematics self-efficacy has not been investigated in this context. Therefore, it is thought that the current research will contribute the concerning literature. The aim of the study is to investigate the effect of mathematics self-efficacy belief on anxiety of teaching mathematics.

Methods: The participants of the study consist of 42 mathematics teacher candidates in the Department of Mathematics Education, Faculty of Education. The scale of mathematics self-efficacy, developed by Umay (2001), and the scale of mathematics teaching anxiety, developed by Peker (2006), were enrolled as measurement tools. Pearson correlation was used for the correlation between teacher candidates' average points from the both scales.

Results: The results revealed that there was a significant and negative correlation mathematics self-efficacy beliefs and anxiety of teaching mathematics. This result means that the students' mathematics teaching anxiety decrease as their mathematics self-efficacy beliefs increases. On the other hand, it was seen that mathematics selfefficacy belief explains 35\% of the variance in teaching mathematics anxiety. Besides, it was determined that mathematics teacher candidates' mathematics teaching anxiety was at low level, and mathematics efficacy beliefs are at high level.

Discussion and Conclusions: The factors in the scale of the Anxiety of Teaching Mathematics are "Content knowledge", "self confidence”, "attitudes towards teaching mathematics", "Pedagogical knowledge". Also, the most affective factor that cause the Anxiety of Teaching Mathematics is content knowledge. On the other hand, the most 
important factor that affect self-efficacy is individual experiences, performances as Bandura (1986) stated. Hackett and Betz (1989) defined mathematics self-efficacy as a situational or problem-specific assessment of an individual's confidence in her or his ability to successfully perform or accomplish a particular mathematical task or problem. Therefore, the most important factor that affect mathematics self-efficacy is individual performances at mathematical works. There is no doubt that the most important factor affecting this performance is conceptual and procedural mathematical knowledge and also problem solving ability or briefly mathematical power of person. From this views; it is understandable that mathematics self-efficacy affects the anxiety of teaching mathematics at a significant level. In terms of the findings of the current research, it can be suggested with regard to education of the pre-service math teachers that the knowledge of math teacher candidates about mathematical concepts and operations, teaching methods, their abilities of problem solving must be enhanced to make their beliefs about mathematics self-efficacy. Thus, their anxiety of teaching mathematics will decrease. 


\title{
Matematik Öz-yeterlik Algısının Matematik Öğretmeye Yönelik Kaygıya Etkisi
}

\begin{abstract}
Alattin URAL*
Makale Gönderme Tarihi: 09 Eylül 2014

Makale Kabul Tarihi: 06 Şubat 2015

ÖZET: Bu çalışma matematik öz-yeterlik algısının, matematik öğretme kaygısına etkisini incelemek için yapılmıştır. Araştırmanın örneklemini, bir devlet üniversitesinin matematik öğretmenliği bölümünde okumakta olan 42 son sınıf öğrencisi oluşturmaktadır. Öğretmen adaylarının matematik öz-yeterlik algılarını ölçmek için Umay (2001) tarafından geliştirilen ölçek ve matematik öğretmeye yönelik kaygılarını ölçmek için Peker (2006) tarafindan geliştirilen ölçek kullanılmıştır. Öğretmen adaylarının öz-yeterlik algısı toplam puanları ortalamaları ile matematik öğretmeye yönelik kaygı toplam puanları ortalamaları arasındaki ilişkiye Pearson korelasyon ile bakılmış ve $r=-0,59$ bulunmuştur. Bu sonuç aralarında negatif yönlü ve orta kuvvetli bir ilişkinin varlığına işaret etmekte ve kaygıdaki değişimin \%35' ini açıklamaktadır. Bu ilişkinin $\mathrm{p}=.01$ düzeyinde anlamlı olduğu belirlenmiştir. $\mathrm{Bu}$ durumda, matematik öz-yeterlik algısı ile matematik öğretmeye yönelik kaygı arasında negatif yönlü ve anlamlı bir ilişki söz konusudur. Diğer taraftan, öğretmen adaylarının matematik öğretmeye karşı kaygılarının düşük (2) ve matematik özyeterlik algılarının ise yüksek (4) olduğu tespit edilmiştir. Matematikte özyeterlilik bir kişinin matematikle ilgili görevleri başarıyla tamamlaması için kendi yeteneğine dair inançları şeklinde tanımlanır ve büyük ölçüde kişinin kendi geçmiş performanslarından etkilenir. Dolayısıyla, öğretmen adaylarının matematiksel kavramlar hakkında hem işlemsel hem kavramsal anlamda bilgi ve becerilerinin geliştirilmesi ve bunun yanında matematiksel görevleri yapabilecekleri noktasında kendilerine güvenlerinin artırılması gerekmektedir.
\end{abstract}

Anahtar sözcükler: matematik özyeterlik algısı, matematik öğretme kaygısı, öğretmen adayları.

\section{Giriş}

Matematik kaygısı ile matematik öğretme kaygısı, aralarında ilişki olmakla beraber farklı kavramlardır. Matematik kaygis1, Richardson \& Suinn (1972) tarafindan "günlük hayatta ve akademik çalı̧̧malarda sayıların kullanımını ve matematiksel problemlerin çözümünü engelleyen gerginlik ve kaygı duygusu" olarak tanımlanmaktadır. Gardner \& Leak (1994) öğretme kaygısını; sınıf içi etkinliklerin hazırlığı ve uygulanmasını içeren öğretme süreciyle ilgili yaşanan kaygı olarak tanımlamaktadır. Levine (1993) matematik öğretme kaygısının, öğretmen adaylarının veya öğretmenlerin matematiksel kavram, teorem ve formülleri öğretirken ya da problem çözme sürecinde yaşadıkları gerginlik ve kaygı hisleri olarak tanımlanabileceğini belirtmiştir. $\mathrm{Bu}$ süreçte aşırı gerginlik, yoğunlaşamama, kendi kendine negatif konuşmalar, seslerden kolayca rahatsız olma, öğrencileri duyamama ve ellerin terlemesi gibi tepkiler görülmektedir. Matematik öğretme kaygısı, içeriği organize etmede, zamanı planlamada, öğretme yöntemlerini belirlemede, öğrenme aktivitelerini belirlemede kendini gösterir (Ameen, Guffey \& Jackson 2002; Huber \& Ward, 1969). Peker (2009a), öğretmen adayların sınıfta nasıl görünecekleri, ne yapacakları ve ne söyleyecekleri konusunda oldukça kaygı duyduklarını belirtmiştir.

Matematik öğretme kaygısı ve matematik kaygısı, ilköğretimden yüksek öğretime kadar birçok öğrencinin matematik performansını ve öğrenme sürecini olumsuz etkilemektedir (örn., Bates, Latham \& Kim, 2013; Peker \& Ertekin, 2011; Sherman \& Wither, 2003). Bu değişkenlerin ayrıca matematik öğretmen adaylarının

\footnotetext{
* Yrd. Doç. Dr, Mehmet Akif Ersoy Üniversitesi, Burdur, altnurl@gmail.com
} 
öğrencilere matematik öğretme potansiyelleri üzerinde de büyük bir etkisi bulunmaktadir (Brown, Wetenskow \& Moyer-Packenham, 2012; Bursal \& Paznokas, 2006; Peker \& Ertekin, 2011). Matematik öğretmen adaylarının matematik öğretme kaygısına ve genel anlamda öğretmeye yönelik kaygıları üzerine çeşitli araştırmalar yapılmıştır (Akinsola, 2008; Austin, Wadlington \& Bitner, 1992; Brady \& Bowd, 2005; Gresham, 2007; Gresham, 2008; Levine, 1993; Levine, 1996; Liu, 2008; Malinsky, Ross, Pannells \& McJunkin, 2006; Peker, 2006; Peker, 2008; Peker, 2009a; Peker, 2009b; Peker \& Halat, 2008; Peker \& Halat, 2009; Tooke \& Lindstrom, 1998; Trujillo \& Hadfield, 1999; Uusimaki \& Nason, 2004; Vinson, 2001). Levine (1993; 1996) matematik öğretme kaygısının öğretmen adayları için sıkça karşılaşılan bir korku ve kayg1 olduğunu belirtmiştir. Tooke \& Lindstrom (1998), ilköğretim öğretmen adaylarının matematiğe karşı negatif tutumlarının olduğunu, matematiksel yeteneklerine pek güvenmediklerini ve yüksek matematik kaygısı taşıdıklarını belirtmiştir.

Matematik kaygısını etkileyen faktörler üzerine çeşitli çalışmalar yapılmıştır. Peker (2008), öğretmen adaylarının öğretme aktivitelerinde kullanmak için somut materyaller bulma gereksinimlerinin arttıkça, matematik öğretme kaygılarının da arttığını ifade etmiştir. Matematik öğretmenlerinden öğretebilme konusunda oldukça yeterli olmalarının beklenmesi de bir ölçüde kaygıya neden olmaktadır (Huber \& Ward, 1969; Ameen et. al., 2002). Peker (2006), alan bilgisi, matematiğe ve matematik öğretmeye karşı tutum ve öz güvenin matematik ve matematik öğretme kaygısını etkilediğini bulmuştur. Araştırmalar matematiksel kavramlara yönelik teorik tartışmaların matematik öğretme kaygısı yüksek olan öğretmen adaylarının öğretmeye karşı kaygılarını daha da artırdığını göstermektedir. Öğretme kaygısı, ayrıca öğrencilerin sorularını yanıtlamaktaki zorluklardan da bir ölçüde kaynaklanmaktadır (Ameen et. al., 2002). Akinsola (2008), matematikte problem çözme becerilerindeki yetkinliğin öğretme endişesiyle ters ilişkili olduğunu belirtmiştir. Peker (2009a) tarafından yapılan bir çalışmada, öğrenme stillerinin matematik öğretme kaygısı üzerinde bir etkisinin olduğu belirlenmiştir. Bu kaygı 1raksak öğrenme stili olanlarda en yüksek, yakınsak olanlarda ise en düşük olmuştur. Öğretim stratejileri de matematik ya da matematik öğretimi üzerine öğretmen adaylarının kaygısını etkilemektedir (Levine, 1996; Harper \& Daane, 1998; Vinson, 2001; Bursal \& Paznokas, 2006; Gresham, 2007; Liu, 2008, Peker, 2009c). Madley ve Dorward (2011) tarafından yapılan çalışmada, matematik kaygısı ve matematik öğretme kaygısı arasında pozitif bir ilişki olduğu ortaya konmuştur. Aynı zamanda matematik başarısının artması ile matematik öğretme kaygısının azalması arasında da bir ilişkinin varlığı belirlenmiştir.

Peker (2009b) tarafindan yapılan çalışmada, genişletilmiş mikro öğretim uygulamalarının öğretmen adaylarının matematik öğretme kaygılarını azalttı̆̆ belirlenmiştir. Peker (2006), öğretmen adaylarının manipülatif materyalleri kullanma, matematik öğretmeye yönelik yaratıcı öğretme stratejilerini geliştirme ve matematiksel kavramların öğretimine yönelik ders planı tasarlama konularında becerilerini artırmanın kaygı seviyelerini azalttı̆̆ belirlenmiştir. Benzer şekilde Sloan et al. (2002), manipülatif materyallerin kullanımının kaygıyı azalttı̆̆ını bulmuştur. Vinson (2001), öğretmen 
adaylarına matematiksel kavram ve prosedürler somut bir yolla sunulduklarında anlamakta daha iyi olduklarını belirtmiştir.

Uusimaki \& Nason (2004), öğretmen adaylarının matematiğe karşı negatif inançları ve kaygılarının öğretme uygulamaları üzerinde güçlü bir etkiye sahip olduğunu belirtmiştir. Öğrencideki matematik kaygısı, öğretmendeki matematik öğretme kaygısıyla (Uusumaki \& Nason, 2004) ilişkilidir. Vinson (2001), matematik kaygısı olan öğretmenlerin öğrencileri arasında matematik kaygısının erken gelişiminin hızlanmasına neden olabileceğini belirtmiştir. Dolayısıyla, matematik öğretmen adaylarının matematik ögretme konusunda kendilerini yeterli hissetmelerinin ve kabul edilebilir bir düzeyin üstünde kaygı duymamalarının sağlanması şüphesiz öğretmen yetiştirme sürecinin bir çıktısı olmalıdır. Bunun için yapılması gereken önemli işlerden biri de matematik öğretmen adaylarının matematiksel kavramlar ve işlemler üzerindeki bilgilerinin, problem çözme becerilerinin ve ayrıca matematik öğretim yöntemleri ve teknikleri konusunda bilgi ve becerilerinin yeterli hale getirilmesini sağlamaktır.

Bandura (1986), öz yeterliliği; "insanların belirli performansları yapabilmesi için gerekli faaliyetleri organize edebilme ve uygulayabilmesi açısından kendi kapasiteleriyle ilgili ön görüşleri” şeklinde tanımlamıştır. Özyeterlilik, bireyin yapacağ seçeneklerini, ortaya koyacağı çabayı, zorluklara ne kadar süre dayanabileceğini ve kendini nasıl hissettiğini etkiler (Bandura, 2004). Özyeterliliğin kökeni; kişinin kendi geçmiş performansları, gözlenen modellerin deneyimlerinin tecrübe edilmesi, sözlü ikna ve psikolojik izlerdir (Bandura, 1986). Bireylerin hedeflerine ulaşmasında yeteneklerinin yanı sıra bu yeteneklerini kullanabilmeleri için inançları ve özyeterlilikleri de bulunmalıdır. Olumsuz deneyimler bireylerin kendi kapasitelerine inanmalarına engel olan önemli bir nedendir (Wood \& Bandura, 1986). Özyeterlilik yüksek olduğunda: Daha yüksek hedefler belirlenir ve bunların gerçekleştirilmesi için daha çok bağlı olunur; Kompleks karar verme durumlarında daha etkili ve görev merkezli olunur; Davranışlar için yapıcı yol göstericiler sağlanır; Daha fazla denenir ve ısrarcı olunur; Gelecek için daha olumlu bir görüş açısına sahip olunur (Roediger III, Deutch, Scott, Polivy, Herman, 1996).

Matematikte özyeterlilik bir kişinin matematikle ilgili görevleri başarıyla tamamlaması için kendi yeteneğine dair inançları şeklinde tanımlanır (Cooper \& Robinson, 1991; Hackett \& Betz, 1989; Pajares \& Kranzler, 1995). Hackett \& Betz’in (1989) araştırması, matematik performansı ve matematik özyeterlilik algısının ikisinin de matematiğe karşı tutumla ve matematikle ilgili önemli bir şeyi başarmaya çalışma çabası ile pozitif ve anlamlı pozitif bir korelasyonunun olduğunu göstermiştir. Randhawa, Beamer \& Lundberg (1993) tarafından yapılan araştırmanın sonucunda matematik özyeterlilik algısının matematiğe karşı tutum ile matematik başarısı arasında bir arabulucu değişken olduğu ortaya konmuştur. Pajares \& Kranzler (1995) matematik özyeterlilik algısının matematik kaygısı ve problem çözme performansı üzerinde güçlü bir etkisinin olduğunu rapor etmiştir. Cooper \& Robinson (1991) tarafindan yapılan geçerliliği yüksek bir çalışmada matematik özyeterlilik algısıyla matematik kaygısı ve matematik performansı arasında anlamlı bir ilişki olduğu belirtilmektedir. Bu ilişkinin 
kabulü bireyin özyeterliğini geliştirmek için gerekenlerin neler olduğu konusunda soruları gündeme getirmektedir. Cooper \& Robinson (1994) tarafından belirtilen ifadeyi matematik açısından söylersek, kişinin matematik özyeterlilik algısının artmasını sağlayabilen çevresel faktörlerin keşfedilmesi önemlidir. Betz \& Hackett (1989), sosyal bilişsel teoriye göre matematik kaygısının kaynağının düşük matematik özyeterlilik algısı olduğu belirtmiştir. Cooper \& Robinson (1991), 290 üniversite öğrencisinin matematik özyeterlilik inançları ile matematik kaygısı ve performansları arasındaki ilişkiyi açıklamak için yaptığı araştırmanın sonucunda matematik özyeterliliğin, matematik kaygısı ile negatif, matematik performansıyla pozitif bir korelasyonu olduğunu saptamıştır.

Yapılan çalışmalar incelendiğinde, Matematik Özyeterlik Algısının etki ettiği alanlar arasında Matematik Öğretme Kaygısına rastlanmamıştır. Dolayısıyla bu çalışmanın bu anlamda literatüre bir katkı sunacağı düşünülmektedir.

\section{Yöntem}

Araştırmanın örneklemini, bir devlet üniversitesinin Eğitim Fakültesinin Matematik Eğitimi Anabilim Dalı'nda öğrenim görmekte olan 42 son sınıf matematik öğretmen adayı oluşturmaktadır. Bu çalışmada, matematik öz-yeterlik algısının (bağımsız değişken), matematik öğretmeye yönelik kaygıya (bağımlı değişken) etkisini incelemek için yapılmıştır. "Deneklerin Matematik Özyeterlik Algısı Ölçeğinden aldıkları ortalama puanı ile Matematik Öğretme Kaygısı Ölçeğinden aldıkları ortalama puanları arasında anlamlı bir fark var mıdır?" şeklindeki araştırma sorusuna yanıt aranmıştır. Öğretmen adaylarının bu iki ölçekten aldıkları ortalama puanlar arasındaki ilişkiye Pearson korelasyon ile bakılmıştır.

\section{Veri Toplama Araçları}

Öğretmen adaylarının matematik öz-yeterlik algılarını ölçmek için Umay (2001) tarafından geliştirilen 5-li likert tipi ölçek kullanılmıştır. 14 maddeden oluşan ölçeğin güvenirlik katsayısı $\alpha=.88$ olarak hesaplanmıştır. Ölçeğin maddelerinin geçerlik katsayılarının ortancası .64 bulunmuş, bunun ölçeğin tümünün geçerliği konusunda bir ölçüt olarak kabul edilebileceği düşünülmüştür. Ölçek üç faktörden oluşmaktadır. Bunlar, 1. Matematik benlik algısı, 2. Matematik konularında davranışlarındaki farkındalık ve 3. Matematiği yaşam becerilerine dönüştürebilme olarak tanımlanmıştır.

Matematik öğretmeye yönelik kaygılarını ölçmek için Peker (2006) tarafindan geliştirilen 5-li likert tipi ölçek kullanılmıştır. Ölçeğin tamamının iç tutarlılık güvenirliligi (Cronbach Alpha) .91 olarak belirlenmiştir. Ölçek 4 faktörden oluşmaktadır. Bunlar kısaca: "alan bilgisi”, “özgüveni”, “matematik öğretmeye yönelik tutum", "alan eğitimi bilgisi" şeklindedir. Toplam varyans içinde "alan bilgisi" faktörü \% 35 ile en büyük varyans değerine sahiptir. Diğerleri \%8.55, \%6.57, \%5.97 olarak tespit edilmiştir. 
Araştırma öğretmen adaylarının çocuklardaki fiziksel istismar belirtilerine ilişkin farkındalık düzeylerini incelemeyi amaçladığından, araştırmada Fiziksel İstismar Belirtileri Değerlendirme Formu'nun yalnız birinci bölümü kullanılmıştır.

\section{Bulgular}

Öncelikle öğretmen adaylarının matematik öz-yeterlik ortalama puanları ile matematik öğretme kaygısı ortalama puanlarının eşleştirilmesiyle oluşan saçılım (dağılım) grafiği Şekil 1' de verilmiştir.

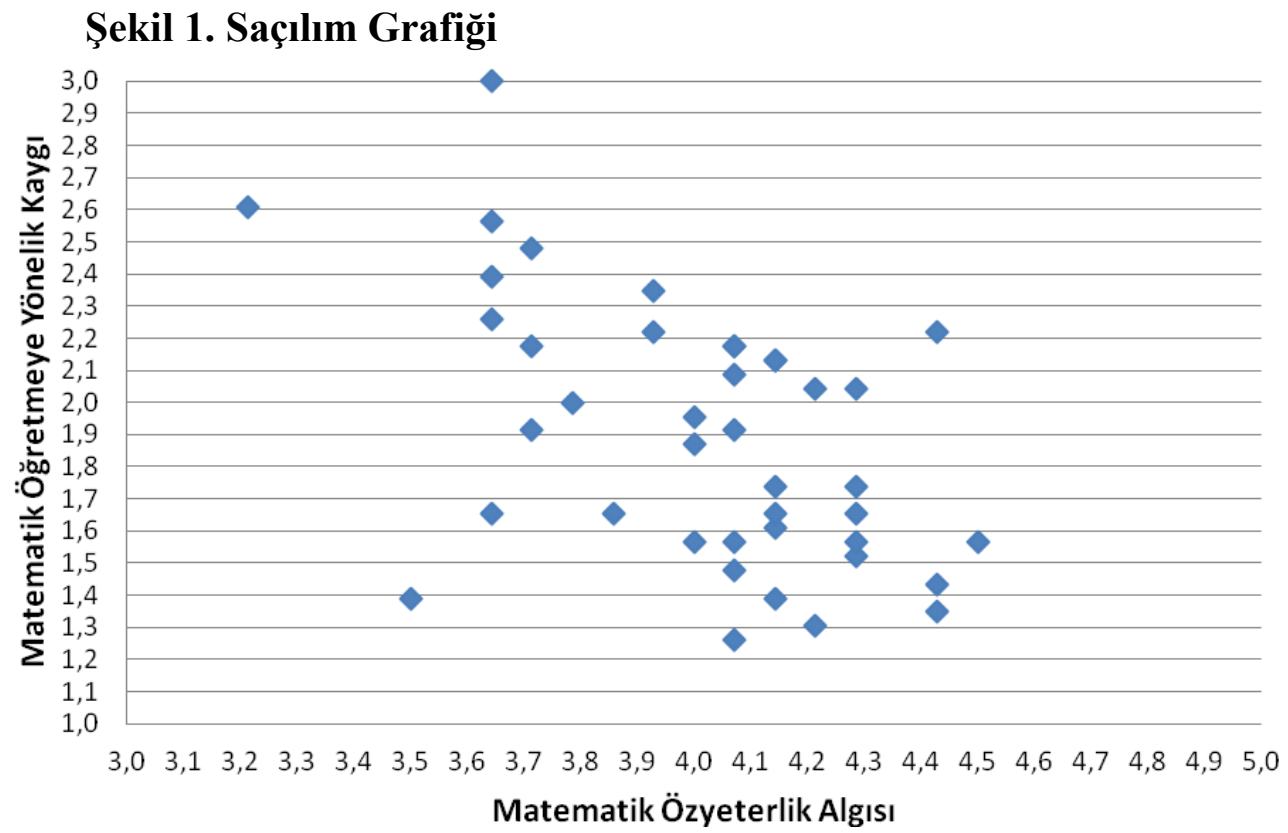

Saçılma grafiğgi incelendiğinde; değişkenler arasında negatif bir ilişki olduğu görülmektedir. $\mathrm{Bu}$ durum, matematik özyeterlik algısına ait değerlerin artması durumunda matematik öğretme kaygısına ait değerlerin düşeceği anlamına gelmektedir. Bu iki değişken arasında anlamlı bir ilişkinin olup olmadığı açısından tek yönlü olarak Pearson Korelasyon Katsayına bakılmış ve anlamlı bir ilişki olduğu görülmüştür [r=-0.59; $\mathrm{p}<0.01]$. $\mathrm{r}$ değerinin 0.50-0.69 arasında olması orta düzeyde bir ilişki olduğunu belirtir. Buna göre matematik özyeterlik algısı yüksek olan öğrencilerin matematik öğretme kaygısının düşük olacağı söylenebilir. $\mathrm{r}$ değerinin karesi toplam bağımlı değişkendeki toplam varyansın oranı vermektedir. Bu durumda, matematik özyeterlik algısının, matematik kaygısındaki değişimin \%35' ini açıkladığı (nedeni olduğu) söylenebilir.

Diğer taraftan, matematik öğretmen adaylarının matematik özyeterlik algısı ölçeğinden ve matematik öğretme kaygısı ölçeğinden aldıkları ortalama puanlar Tablo 1 ' de verilmiştir. 
Tablo 1

Ortalama Puanlar

\begin{tabular}{llcc}
\hline & $N$ & $\overline{\mathrm{X}}$ & \multicolumn{2}{c}{ ss } \\
\hline Matematik Özyeterlik Algısı & 42 & 3.997 & 12.4 \\
\hline Matematik Öğretme Kaygısı & 42 & 1.924 & 13.1 \\
\hline
\end{tabular}

Tablo incelendiğinde, matematik öğretmen adaylarının matematik özyeterlik algılarının ortalamasının yüksek ve matematik öğretmeye karşı kaygılarının ise düşük olduğu görülmektedir.

\section{Sonuç ve Tartışma}

Araştırmanın sonucunda, matematik öğretmen adaylarının matematik öz-yeterlik algısının, matematik öğretmeye yönelik kaygılarını anlamlı ve orta düzeyde etkilediği ve ayrıca, matematik kaygısındaki değişimin \%35'ini açıkladığı belirlenmiştir. Matematik öğretme kaygı ölçeğindeki faktörler, "alan bilgisi”, “özgüven”, “matematik öğretmeye yönelik tutum", "alan eğitimi bilgisi” şeklindedir. Ayrıca bu kaygıya neden olan en önemli faktör de alan bilgisidir. Diğer taraftan, özyeterlik algısını etkileyen faktörlerden en önemlisi Bandura (1986)'nın ifade ettiği gibi kişinin kendi geçmiş performanslarıdır. Dolayısıyla, Matematik Özyeterlik Algısını belirleyen en önemli faktör kişinin geçmiş matematiksel görevlerindeki performansıdır. Şüphesiz bu performansı etkileyen en önemli unsur da kişinin matematiksel kavram ve işlem bilgisi ayrıca problem çözme becerisi kısaca matematiksel gücüdür. Bu açıdan bakıldığında; matematik öz-yeterlik algısının matematik öğretmeye karşı kaygının oluşumunda anlamlı derecede etkili olması anlaşılabilirdir.

Diğer taraftan, matematik öğretmen adaylarının matematik özyeterlik algılarının yüksek ve matematik öğretmeye karşı kaygılarının ise düşük olduğu görülmüştür. Matematik öğretmenliği son sınıfında okuyan öğrencilerin matematiksel bilgilerinin iyi durumda olmasının doğal sonucu olarak matematik özyeterlik algılarının yüksek olması ve buna bağlı olarak da matematik öğretmeye karşı kaygılarının düşük olması beklenen bir durum olarak görülmektedir. 


\section{Kaynakça}

Akinsola, M. K. (2008). Relationship of some psychological variables in predicting problem solving ability of in-service mathematics teachers. The Montana Mathematics Enthusiast, 5(1), 79-100.

Ameen, E. C., Guffey, D. M., \& Jackson, C. (2002). Evidence of teaching anxiety among accounting educators. Journal of Education for Business, 78(1), 16-22.

Austin S., Wadlington, E., \& Bitner, J. (1992). Effect of beliefs about mathematics on math anxiety \& math self-concept in elementary teachers. Education, 112(3), 390396.

Bandura, A. (1986). The explanatory \& predictive scope of self-efficacy theory. Journal of Clinical \& Social Psychology, 4, 359-373.

Bandura, A. (2004). Social cognitive theory of posttraumatic recovery: The role of perceived self-efficacy. Behaviour Research \& Therapy, 42, 1129-1148.

Bates, A. B., Latham, N. I., \& Kim, J. (2013). Do I have to teach math? Early childhood preservice teachers' fears or teaching mathematics. Issues in Undergraduate Mathematics Preparation of School Teachers: The Journal, 5 (Teacher Attributes), August.

Brady, P., \& Bowd, A. (2005). Mathematics anxiety, prior experience \& confidence to teach mathematics among pre-service education students. Teachers \& Teaching: Theory \& Practice, 11(1), 37-46.

Brown, A., Westenskow, A., \& Moyer-Pakenham, P. S. (2012). Teaching anxieties revealed: Pre-service elementary teachers' reflections on their mathematics teaching experiences. Teaching Education, 23(4), 365-385.

Bursal, M., \& Paznokas, L. (2006). Mathematics anxiety \& preservice elementary teachers' confidence to teach mathematics \& science. Sch. Sci. Math. 106(4), 173180.

Cooper, S. E., \& Robinson, D. A. G. (1991). The relationship of mathematics selfefficacy beliefs to mathematics anxiety \& performance. Measurement \& Evaluation in Counseling \& Development, 24(1), 4-11.

Gardner, L., \& Leak, G. (1994). Characteristics \& correlates of teaching anxiety among college psychology teachers. Teaching of Psychology, 21(1), 28-32.

Gresham, G. (2007). A study of mathematics anxiety in preservice teachers. Early Childhood Education Journal, 35(2), 181-188.

Gresham, G. (2008). Mathematics anxiety and mathematics teacher efficacy in elementary pre-service teachers. Teaching Education, 19(3), 171-184.

Hackett, G., \& Betz, N. E. (1989). An exploration of the mathematics selfefficacy/mathematics performance correspondence. Journal for Research in Mathematics Education, 20(3), 261-273. 
Hadley, K. M., \& Dorward, J. (2011). The Relationship among elementary teachers' mathematics anxiety, mathematics instructional practices, and student mathematics achievement. Journal of Curriculum and Instruction, 5(2), 27-44.

Harper N. W., \& Daane, C. J. (1998). Causes and reduction of math anxiety in preservice elementary teachers. Act. Teach. Educ. 19(4), 29-38.

Huber, J., \& Ward, B. E. (1969). Pre-service confidence through microteaching. Education, 90(1), 65-68.

Levine, G. (1993, October). Prior mathematics history, anticipated mathematics teaching style, and anxiety for teaching mathematics among pre-service elementary school teachers. Paper presented at the Annual Meeting of the 15th International Group for Psychology of Mathematics Education. North American Chapter., Asilomar, CA.

Levine, G. (1996, April). Variability in anxiety for teaching mathematics among preservice elementary school teachers enrolled in a mathematics course. Paper presented at the Annual Meeting of the American Educational Research Assocation in New York (ERIC Document Reproduction Service No. ED398067).

Liu, F. (2008). Impact of online discussion on elementary teacher candidates' anxiety towards teaching mathematics. Education, 128(4), 614-629.

Malinsky, M., Ross, A., Pannells, T. \& McJunkin, M. (2006). Math Anxiety in preservice elementary school teachers. Education, 127(2), 274-279.

Pajares, F., \& Kranzler, J. (1995). Self-efficacy beliefs and general mental ability in mathematical problem-solving. Contemporary Educational Psychology, 20, 426443.

Peker, M. (2006). Matematik öğretmeye yönelik kaygı ölçeğinin geliştirilmesi. Eğitim Bilimleri ve Uygulama, 9, 73-92.

Peker, M. (2008, Ağustos). Ĕgitim programları ve ögretmen adaylarının matematik ögretme kaygısı. VIII. Ulusal Fen Bilimleri ve Matematik Eğitimi Kongresi’nde sunulmuş bildir, Bolu, Türkiye.

Peker, M. (2009a). Pre-service mathematics teacher perspectives about the expanded microteaching experiences. J. Turk. Educ. Sci. 7(2), 353-376.

Peker, M. (2009b). Pre-service teachers' teaching anxiety about mathematics and their learning styles. Eurasia J. Math. Sci. Tech. Educ. Eurasia Journal of Mathematics, Science \& Technology Education, 5(4), 335-345.

Peker, M. (2009c). The Effects of an instruction using problem solving strategies in mathematics on the teaching anxiety level of the pre-service primary school teachers. The New Educational Review, 18, 95-114.

Peker, M., \& Ertekin, E. (2011). The relationship between mathematics teaching anxiety and mathematics anxiety. The New Educational Review, 23(1), 213-226. 
Peker, M., \& Halat, E. (2008, September). The pre-service teachers' mathematics teaching anxiety and gender. Paper presented in The European Conference on Educational Research, Gothenburg, Sweden.

Peker, M., \& Halat, E. (2009). Teaching anxiety and the mathematical representations developed through webquest and spreadsheet activities. Journal of Applied Sciences, 9(7), 1301-1308.

Randhawa, B., Beamer, J., \& Lundberg, I. (1993). Role of mathematics self-efficacy in the structural model of mathematics achievement. Journal of Educational Psychology, 85, 41-48.

Richardson, F. C., \& Suinn, R. M. (1972). The mathematics anxiety rating scale: psychometric data. Journal of Counseling Psychology, 19, 551-554.

Roediger, H. L., Capaldi, E. D., Paris, S. G., Polivy, J., \& Herman, C. P. (1996). Psychology (4th Ed.).. St. Paul, MN: West Publishing Co.

Sloan, T., Daane, C. J., \& Giesen, J. (2002). Mathematics anxiety and learning styles: What is the relationship in elementary preservice teachers? School Science \& Mathematics, 102(2), 84-87.

Tooke, D. J., \& Lindstrom, L. C. (1998). Effectiveness of a mathematics methods course in reducing math anxiety of preservice elementary teachers. School Science \& Mathematics, 98(3), 136-139.

Trujillo, K. M., \& Hadfield, O. D. (1999). Tracing the roots of mathematics anxiety through in-depth interviews with preservice elementary teachers. College Student Journal, 33(2), 219-232.

Umay, A. (2001). İlköğretim matematik öğretmenliği programının matematiğe karş1 özyeterlik algısına etkisi. Journal of Qafqaz University, 8(1).

Uusimaki, L., \& Nason, R. (2004). Causes underlying pre-service teachers' negative beliefs and anxieties about mathematics. Proceedings of the 28th Conference of the International Group for the Psychology of Mathematics Education, 4, 369-376.

Vinson, B. M. (2001). A comparison of preservice teachers' mathematics anxiety before and after a methods class emphasizing manipulatives. Early Childhood Education Journal, 29(2), 89-94. 